\title{
Review
}

\section{The diabetic foot: from art to science. The 18th Camillo Golgi lecture}

\author{
A. J. M. Boulton ${ }^{1,2}$ \\ ${ }^{1}$ Department of Medicine, Manchester Royal Infirmary, UK \\ ${ }^{2}$ Division of Endocrinology, University of Miami, Florida, USA
}

\section{Abstract}

Diabetic foot ulceration represents a major medical, social and economic problem all over the world. While more than $5 \%$ of diabetic patients have a history of foot ulceration, the cumulative lifetime incidence may be as high as $15 \%$. Ethnic differences exist in both ulcer and amputation incidences, with both being less common in patients of Indian subcontinent origin living in the UK. Foot ulceration results from the interaction of several contributory factors, the most important of which is neuropathy. With respect to the management of acute Charcot neuroarthropathy in diabetes, recent studies suggest that bisphosphonates reduce disease activity as judged not only by differences in skin temperature, but also by assessing markers of bone turnover. The use of the total-contact cast is demonstrated in the treatment of acute Charcot feet and of plantar neuropathic ulcers. Histological evidence suggests that pressure relief results in chronic foot ulcers changing their morphological appearance by displaying some features of an acute wound. Thus, repetitive stresses on the insensate foot appear to play a major role in maintaining ulcer chronicity. It is hoped that increasing research activity in foot disease will ultimately result in fewer ulcers and less amputation in diabetes.

Keywords Charcot neuroarthropathy - Diabetic foot . Diabetic neuropathy · Epidemiology $\cdot$ Wound healing

\section{Introduction}

It was over one hundred years ago that Pryce, a surgeon working in Nottingham, England, recognised the connection between diabetes and foot ulceration: "Diabetes itself may play an active part in the causation of perforating ulcers" he wrote in the Lancet, and fur-

Received: 8 April 2004 / Accepted: 21 June 2004

Published online: 28 July 2004

C) Springer-Verlag 2004

\author{
A. J. M. Boulton (凶) \\ Department of Medicine, Manchester Royal Infirmary, \\ Oxford Road, Manchester, M13 9WL, UK \\ E-mail: Andrew.j.boulton@man.ac.uk \\ Tel.: +44-161-2764452, Fax: +44-161-2744740
}

Abbreviations: BSAP, bone-specific alkaline phosphatase $\mathrm{CN}$, Charcot neuroarthropathy $\cdot \mathrm{RCW}$, removable cast walker · TCC, total-contact cast ther "it is abundantly evident that the actual cause of the perforating ulcers was a peripheral nerve degeneration" $[1,2]$. However, it was Paul Brand (1914-2003) who added science to the art of foot care $[3,4,5]$. When he spoke at a US Department of Health conference and was asked to make a recommendation on reducing amputation in diabetes, most listeners expected an answer promoting vascular surgery or modern medications. They were surprised to hear that his key recommendation was a national campaign to encourage physicians to remove patients' shoes and socks and to examine the feet [3]. Although always emphasising the art of clinical medicine in his work, Brand also performed pioneering research looking at abnormal foot pressures during walking, and he described the use of thermography in assessing areas at risk of imminent breakdown $[4,5]$.

Progress in our understanding of the pathogenesis and management of the diabetic foot has been made in the last 20 years. This has been matched by an in- 
creasing number of publications in peer-reviewed journals. Taken as a percentage of all Pub-Med listed papers on diabetes, papers on the diabetic foot have increased from $0.7 \%$ in the $1980-88$ period to more than $2.7 \%$ in the last 6 years. During the same time period, foot councils and study groups have been formed in the EASD and the ADA, and the International Working Group has published an international consensus booklet on the diabetic foot [6].

This review will discuss the epidemiology of foot problems, causal pathways that result in ulceration, the importance of foot pressures, Charcot neuroarthropathy, an update on wound healing, and finally a description of international developments and efforts to improve the management of the diabetic foot.

\section{Epidemiology}

The study of the epidemiology of diabetic foot disease has been beset by numerous problems relating to diagnostic tests and population selection [7, 8]. Until proper population-based registers of people with diabetes are available, reliable data relating to accurate estimates of the prevalence and incidence of these late complications will be limited. It is clear, however, that foot ulcers and amputations remain common and serious complications of both main types of diabetes, which are associated with significant mortality $[9,10]$. Useful definitions for these two conditions are as follows [9]: foot ulcers are lesions that involve a skin break with loss of epithelium, and that may extend into the dermis and deeper layers, sometimes involving bone and muscle; amputation is the removal of a terminal, non-viable portion of the limb.

A selection of recent epidemiological data $[11,12$, $13,14,15,16,17]$ on ulceration and amputation is listed in Table 1. Two studies from northern European countries reported the annual incidence of foot ulcers in the general diabetes population to be just over $2 \%$ $[12,13]$. Ulceration is much more common in patients with predisposing risk factors; annual incidence rates in neuropathic individuals vary from $5 \%$ to over $7 \%$ $[18,19]$. It is likely that more than $5 \%$ of diabetic patients have a history of foot ulcers [11], whereas the cumulative lifetime incidence may be as high as $15 \%$ [9].

Up to $85 \%$ of amputations are preceded by foot ulcers. It can therefore be presumed that any successes in reducing foot ulcer incidence will be followed by a reduction in the number of amputations. To date, studies in Europe, with the exception of a study in Sweden [20], have been disappointing in this respect. Studies from Germany have shown no evidence of a decrease in amputation in the last decade [21,22], whereas one report from the UK actually reported an increase [23].

Ethnicity and ulceration/amputation. Studies from the UK suggest that foot ulcers and amputations are less common in Asian patients of Indian subcontinent origin $[24,25]$, whereas Afro-Caribbean males, but not females, have lower amputation rates [26]. Possible explanations for the findings in Asian patients relate to differences in limited joint mobility, and to better foot care in certain religious groups such as Muslims. In contrast, Resnick et al. [27] reported that amputation rates were more common amongst black subjects with diabetes than in white Americans. Similarly, ulceration was much more common in Hispanic Americans and in native Americans than in non-Hispanic whites [14].

Costs of ulceration/amputation. One of several reasons that resulted in the American Diabetes Association holding a consensus conference on diabetic wound care in 1999 was the vast cost of diabetic foot disease, and the real need to develop cost-effective measures to treat and prevent ulcers [28]. More recently, Shearer et al. [29] confirmed that diabetic patients with neuropathic risk factors (reduced vibration perception) incur five times more direct medical costs for ulcers and amputations, and live for 2 months less,

Table 1. Epidemiology of diabetic foot ulceration

\begin{tabular}{|c|c|c|c|c|c|c|c|c|}
\hline \multirow[t]{2}{*}{ Author } & \multirow[t]{2}{*}{ Year } & \multirow[t]{2}{*}{ No. } & \multirow[t]{2}{*}{ Ref. } & \multirow[t]{2}{*}{ Country } & \multicolumn{2}{|c|}{ Prevalence } & \multicolumn{2}{|c|}{ Incidence } \\
\hline & & & & & Ulcer & Amputation & Ulcer & Amputation \\
\hline Kumar et al. & 1994 & 811 & {$[11]$} & UK & 1.4 & 1.4 & & \\
\hline Abbott et al. & 2002 & 9710 & {$[12]$} & UK & 1.7 & 1.3 & 2.2 & \\
\hline Mueller et al. & 2002 & 665 & [13] & NL & & & 2.1 & 0.6 \\
\hline \multicolumn{9}{|l|}{ Global } \\
\hline Humphrey et al. & 1996 & 1564 & {$[15]$} & Nauru, Pacific region & & & & 0.76 \\
\hline Belhadj* & 1998 & 865 & [16] & Algeria & 11.9 & 6.7 & & \\
\hline Pendsey* & 1994 & 11,300 & {$[17]$} & India & 3.6 & & & \\
\hline
\end{tabular}

Studies are population- or community-based, except $*=$ clinic based; NL, The Netherlands 
than individuals without neuropathy. Similarly, a Swedish study reported that an intensified prevention strategy involving education, foot care and footwear would be cost-effective and even cost-saving if applied to patients with risk factors [30].

Average inpatient costs for lower limb complications in 1997 were: foot ulcers $\$ 16,580$; toe or toe and other distal amputations $\$ 25,241$; major amputations $\$ 31,436$ [31]. The average outpatient cost for one diabetic foot ulcer episode has been estimated at $\$ 28,000$ over a 2-year period [32].

\section{Causal pathways to foot ulceration}

Foot ulcers rarely result from a single pathology. It is rather the interaction of two or more contributory causes that lead to the breakdown of the high-risk foot [33]. The neuropathic foot, for example, does not spontaneously ulcerate; it is the combination of insensitivity and either extrinsic factors (e.g. walking bare foot and stepping on a sharp object, or simply wearing ill-fitting shoes) or intrinsic factors (e.g. patient with insensitivity and callus who walks and develops an ulcer) that ultimately results in ulceration. Neuropathy is the most important contributory cause in the pathway to ulceration [34], discussed below along with other causes.

Neuropathy. The association between both somatic and autonomic neuropathy and foot ulceration has been recognised for many years [35]. It is only in the last decade that prospective follow-up studies have confirmed this causative role of somatic neuropathy $[12,18,19]$. Patients with sensory loss appear to show an increase in risk of developing foot ulcers of up to seven-fold, compared with non-neuropathic diabetic individuals. Poor balance and instability are increasingly being recognised as troublesome symptoms of peripheral neuropathy, presumably secondary to proprioceptive loss. The relationship between sway, postural instability and foot ulceration has been confirmed [36, 37].

Peripheral autonomic (sympathetic) dysfunction results in dry skin and, in the absence of peripheral vascular disease, a warm foot with distended dorsal foot veins. This may pose problems in terms of patient education as there is a strong lay belief that all foot problems result from vascular disease. Thus, patients may find it difficult to accept that their warm but painfree feet are at significant risk of unperceived trauma and subsequent ulceration [38].

In practice, peripheral neuropathy can easily be documented by a simple clinical assessment of large fibre function (e.g. loss of vibration perception using a $128-\mathrm{Hz}$ tuning fork), small fibre function (e.g. hot-cold rods and/or pin-prick sensation) in the feet, together with assessment of ankle reflexes [12, 39]. A composite score comprising these clinical measures, the modified neuropathy disability score, has been shown to be useful in the prediction of those at risk of future ulceration [12]. The 10-g monofilament, used to test pressure perception, is frequently employed to assess diabetic patients' foot ulcer risk status [40]. Although simple to perform, care must be taken to ensure that the filaments used are accurate in delivering a 10-g force when used [41]. Moreover, it has also been suggested that the widespread use of filaments needs to be reappraised as this may not be the most sensitive test [42].

For clinical research, electrophysiology (e.g. peroneal nerve conduction velocity) has been shown to be an excellent surrogate endpoint for foot ulceration in trials of agents that might influence the natural history of neuropathy [43].

Peripheral vascular disease. Peripheral ischaemia resulting from proximal arterial disease was given as a component cause in the pathway to ulceration in $35 \%$ of cases in the two-centre study of causal pathways [34]. A recent comparative study of peripheral arterial disease in diabetic and non-diabetic patients confirmed that diabetic patients had more distal disease and a poorer outcome with respect to amputation and mortality [44]. The ischaemic foot is red, dry and often neuropathic. It is therefore susceptible to pressure from, for example, footwear.

Other risk factors. The presence of foot deformity, particularly claw toes and prominent metatarsal heads, is a proven risk factor for ulceration $[34,45]$. Similarly, plantar callus accumulation was associated with a 77 -fold increase in risk in one cross-sectional study. However, in the follow-up of the same patients, plantar ulcers only occurred at sites of callus in neuropathic feet, representing an infinite increase in risk [46].

Other risk factors include the presence of the following: other microvascular complications, increasing duration of diabetes, increases in plantar foot pressures (see below), peripheral oedema, and most predictive of all, a past history of foot ulcers or amputation [33].

Prevention of foot ulcers amongst those identified as having risk factors is pivotal if the high incidence of ulcers is to be reduced, especially as more than $80 \%$ of amputations are preceded by ulcers. Unfortunately, a systematic review of studies of preventative foot care education was unable to confirm the usefulness of education [47]. There is, however, a suggestion that education and regular podiatric care may result in earlier presentation when ulcers develop [48].

Most of the studies referred to in this section report on physical factors that contribute to ulcer development. As discussed by Vileikyte [38], there have been very few studies of psychosocial factors in the pathway to ulcers. It appears that patients' behaviour is 


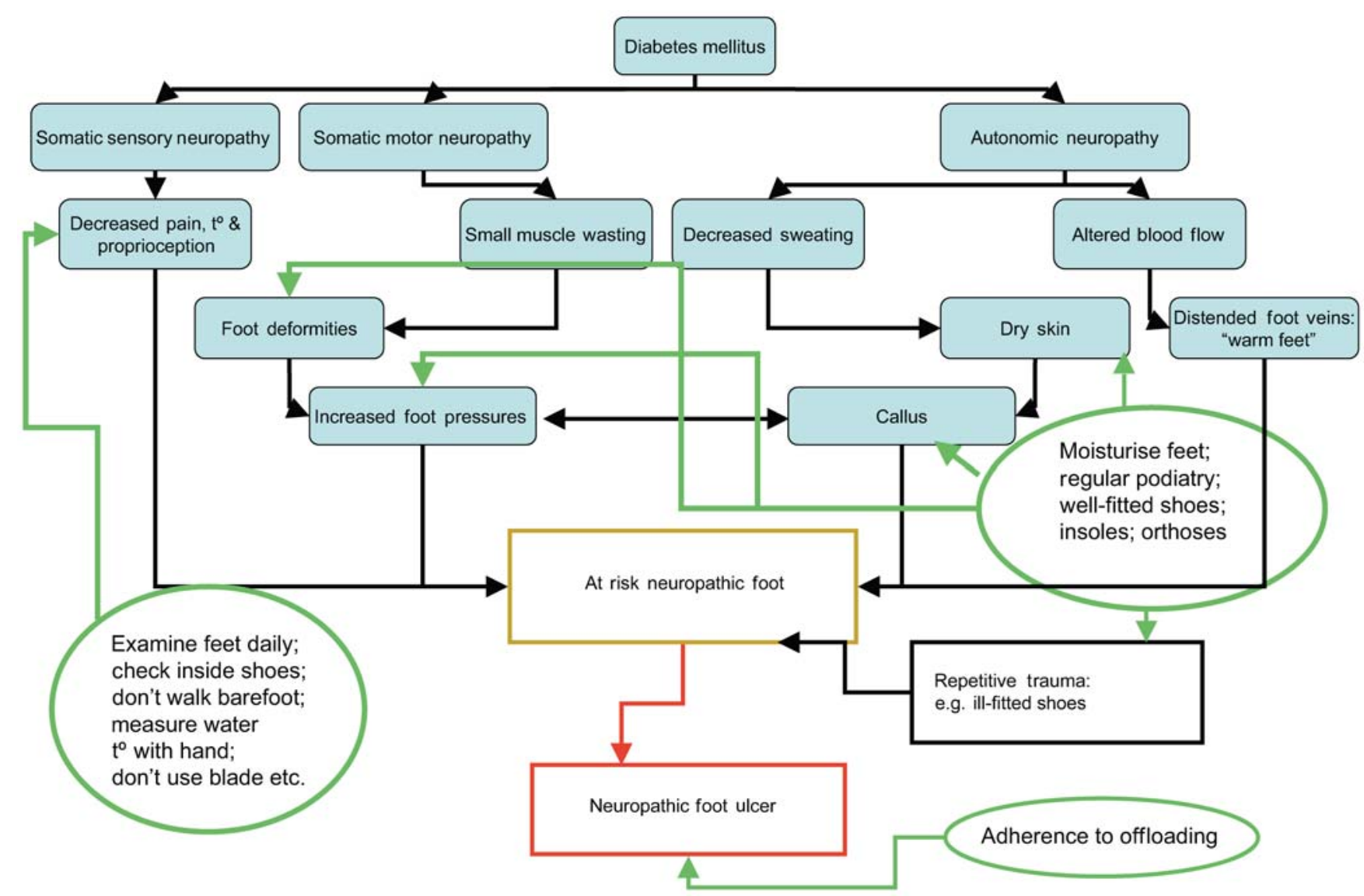

Fig. 1. Causal pathways to foot ulceration emphasising the key role of the patient in ulcer prevention (spheres and arrows); $\mathrm{t}$, temperature. Illustration courtesy of L. Vileikyte

driven not by the abstract designation of being "at risk", but by the patients' own perceptions of their risks. Thus, if patients do not believe that a foot ulcer lies on the path from neuropathy to amputation, are they likely to follow educational advice on how to reduce ulcer risk? [49]. It is clear that research in this area is urgently required. A pathway to foot ulceration including areas where psychosocial factors are relevant is presented in Figure 1.

\section{Foot pressure studies in diabetes}

Using the optical pedobarograph [50], a number of studies were performed over a 10 -year period to investigate the relationship between plantar foot pressures, neuropathy and foot ulceration. After our initial confirmation that plantar ulcers invariably occurred at sites of high pressure [35], we demonstrated that foot pressure abnormalities occur early in the natural history of neuropathy [51]. In a longitudinal study it was confirmed that sites of peak pressure change over time, an observation with important implications for orthotists [52]. The observation of a reduced hyper- aemic response under high-pressure areas suggested that skin breakdown resulted from repetitive pressure (as in walking) under areas such as the metatarsal heads, with a failure of blood flow recovery between footsteps [53]. In a comparative study in patients with rheumatoid feet [54], high foot pressures were common in both diabetic and rheumatoid groups, confirming that high pressures alone do not result in ulceration. It is the combination of pressure and insensitivity that completes the causal pathway.

Subsequently, a cross-sectional study confirmed the need for adequate debridement in the management of neuropathic ulcers; callus removal was demonstrated to result in a significant reduction of foot pressure [55]. Finally, a prospective study confirmed that high foot pressures predict ulcer development in the insensate foot [56].

However, subsequent studies have suggested that other risk factors, such as callus, are more predictive of future ulceration [46], and that foot pressure is a poor tool when used alone to predict ulceration [57].

Alternatives to foot pressure measurement. Although studies using the optical pedobarograph and other foot pressure assessment devices [58] have helped in the understanding of foot ulcer pathogenesis, they are not suited to day-to-day clinical practice in busy diabetic foot clinics. Thus, a simple inexpensive, but reliable, method for screening feet could be helpful to both 


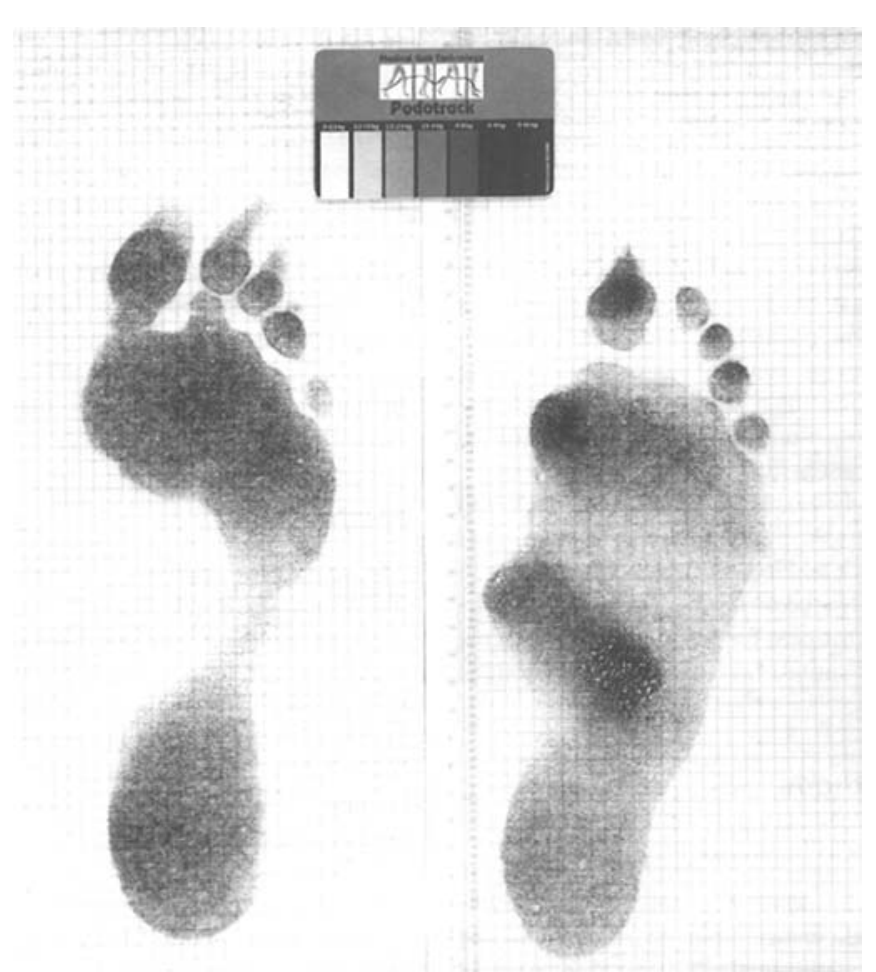

Fig. 2. Two examples of footprints recorded using the Podotrack (PressureStat System). A normal foot is depicted on the left, with an abnormal example of a patient with Charcot neuroarthropathy on the right, showing high pressures (darker areas) under the hallux, first metatarsal head and the bony prominence in the cuneiform-metatarsal region. The calibration card is shown at the top centre of the figure (reproduced, with permission, from reference [59])

physicians and patients. Such a semi-quantitative method, the Podotrack footprint system, was developed in The Netherlands. The Podotrack footprint system (PressureStat in the USA) is a semi-quantitative footprint mat that quantifies plantar pressure by visual comparison of the greyness of the footprint with the calibration card [59]. In a comparative study with the gold standard, the optical pedobarograph, van Schie et al. confirmed that trained observers correctly identified high-pressure areas using the Podotrack, the results of which correlated well with those of the pedobarograph, suggesting that this system could be a useful screening tool [59]. Moreover, the visual impact on the patient (dark area $=$ danger of ulceration) could be used as an educational aid (Fig. 2).

The development of a new ultrasound technique for the measurement of plantar tissue thickness provides a potential surrogate measure of plantar foot pressures. The Planscan platform [60] allows dynamic ultrasound measurement of plantar tissue thickness while the patient is bearing weight. In a comparative study using this technique and plantar pressures measured using the pedobarograph [61], Abouaesha et al. demonstrated that plantar tissue thickness under the metatarsal heads is inversely correlated with dynamic foot pressures. A follow-up study confirmed that high plantar pressure can be predicted from plantar tissue thickness with high sensitivity and specificity [62]. Thus, measurement of plantar tissue thickness by ultrasound provides an alternative means of assessing risk of ulceration in neuropathic patients in clinics without sophisticated foot pressure measurement systems.

Interventions to reduce foot pressures. A number of interventions have been used to reduce or at least redistribute pressure under the feet, particularly on the metatarsal heads. These include sport shoes, extradepth shoes and custom-moulded shoes, sometimes with the addition of a rigid or Rocher sole, according to the deformity [58]. A number of orthotic devices inserted into specialist footwear have also been described.

Two other approaches to reducing foot pressures, special hosiery and injected liquid silicone, have also been researched and will be described in greater detail.

Special hosiery. The observation that the use of special padded hosiery could reduce blister formation in long-distance runners [63] suggested that similar socks might be beneficial to diabetic neuropathic patients. Initial studies in high-risk diabetic neuropathic patients with elevated foot pressures suggested that the use of specially designed padded hosiery could reduce dynamic foot pressures by up to $33 \%$ [64]. The potential usefulness of such hosiery was subsequently confirmed in a longitudinal multi-centre study [65]. The clinical use of this and similar pressure-reducing hosiery is currently under active investigation.

Injected liquid silicone. As noted above, previous studies have confirmed that reduction of subcutaneous tissue under the metatarsal heads of neuropathic patients is associated with increased dynamic foot pressures and consequent increased risk of foot ulcer [61, 62]. Previous anecdotal reports had suggested that the injection of liquid silicone under high-pressure areas of neuropathic feet, thereby increasing the protective "padding", was associated with reduced ulcer formation [66]. A randomised, double-blind trial of injected liquid silicone in the diabetic foot was later carried out in an attempt to confirm these earlier observations. Van Schie et al. [67] confirmed that silicone injections were associated with increased sub-metatarsal head soft-tissue thickness, decreases in foot pressures and reduced callus formation. Thus, the use of an "injectable orthosis" might well be beneficial in high-risk patients. Subsequent follow-up studies confirmed that the patients at greatest risk of ulceration (those with the highest baseline foot pressures) were most likely to benefit from silicone injections [68], but that after 2 years of follow-up, the benefits of injections, though 
still demonstrable, were reduced in comparison with baseline, suggesting that booster injection may be needed periodically [69]. This too is an area of current research.

\section{Charcot neuroarthropathy}

Originally described in patients with tabes dorsalis, a Charcot joint can be defined as one in which there is the simultaneous presence of bone and joint destruction, fragmentation and remodelling [70]. Today, diabetes is the commonest cause of Charcot neuroarthropathy $(\mathrm{CN})$ in western countries. The initiating event of the Charcot process is typically a seemingly trivial injury, which may result in a minor peri-articular fracture, or even a major fracture. Both somatic and autonomic peripheral neuropathy are believed to be prerequisites for the development of CN. Somatic neuropathy allows repeated insensate injury to go unnoticed, and autonomic dysfunction, in the absence of proximal arterial disease, results in increased peripheral blood flow with arterio-venous shunting, perhaps even in bone. Although Young et al. demonstrated reduced bone mineral density in the involved limbs of diabetic patients with $\mathrm{CN}$ [71], prospective studies are required to see whether localised osteopaenia increases the risk of developing $\mathrm{CN}$.

The treatment of $\mathrm{CN}$ depends on the stage during which it is diagnosed. Although up to $50 \%$ of patients do experience pain or discomfort in the acute phase, the diagnosis is often made too late to arrest the destructive changes in bones and joints [70]. The presence of unilateral heat and swelling in a neuropathic diabetic patient should be presumed due to acute $\mathrm{CN}$ until proven otherwise. The management was until recently further hampered by the lack of any randomised trials at any stage of $\mathrm{CN}$. The essence of treatment in the acute phase remains non-weight-bearing immobilisation in a total-contact or removable cast walker.

We were impressed by observations of similarities between acute $\mathrm{CN}$ and reflex sympathetic dystrophy. The suggestion that treatment with bisphosphonates might be useful in the management of this latter condition resulted in a preliminary pilot study of Pamidronate in acute CN [72]. Bisphosphonates are potent inhibitors of osteoclast activation, and as such, might reduce disease activity in the acute phase when bone turnover markers are known to be increased [73, 74]. In this pilot study, the first to address the underlying disease process, symptoms improved and there was normalisation of the skin temperature differential between acute and non-involved feet, as well as a fall in bone turnover, as judged by alkaline phosphatase [72]. These observations resulted in a randomised, double-blind trial of intravenous Pamidronate versus placebo in acute $\mathrm{CN}$ [75]. The confirmation by
McGill et al. [76] that skin temperature differential closely mirrors $\mathrm{CN}$ disease activity as measured by isotope bone scans, justified the use of skin temperature differential as a primary endpoint in this trial. Other endpoints included bone-specific alkaline phosphatase (BSAP) and urinary dehyroxypyridinoline, markers of bone formation and resorption respectively. Pamidronate resulted in a significant reduction in symptoms and bone turnover markers compared with the placebo, but in both groups there were significant reductions in skin temperature differential compared with baseline. It was concluded that Pamidronate was the first pharmacological treatment with proven efficacy in acute $\mathrm{CN}$. The improvement in skin temperature differential in the placebo group was deemed to be a result of effective offloading. Trials of oral bisphosphonates in acute $\mathrm{CN}$ are currently in progress.

Thus, although the true pathogenetic mechanisms that act together to result in $\mathrm{CN}$ remain to be clarified, progress towards specific pharmacological treatments for acute $\mathrm{CN}$ has been made.

\section{Wound healing and the importance of offloading}

Wound healing is a tissue response to injury and passes through the phases of inflammation, chemotaxis, cellular proliferation, extracellular matrix deposition, and finally wound remodelling and scarring [77]. Diabetes may influence foot wound healing in many ways, including an impairment of peripheral circulation, altered leucocyte function, disturbed balance of cytokines and proteases, and even chronic hyperglycaemia itself $[78,79,80]$. However, until recently, the role of offloading in impaired wound healing has not been considered [81].

Rationale for assessment of role of offloading. A normal individual with a foot wound will limp to avoid putting pressure on the wound as this is painful, hence the early observation in leprosy that a patient who walks on a plantar wound without limping must have neuropathy [3]. The peripheral loss of sensation in patients with diabetes and leprosy was therefore believed to permit weight-bearing on an active plantar ulcer, which in turn was believed to impair healing and promote the chronicity of the ulcer [2, 3]. The problem was summarised by Brand who said the following when referring to the neuropathic ulcer: "Dressings and bandages deceive both the doctor and the patient into thinking that by dressing the ulcer, they were curing it". Brand therefore promoted the use of total-contact casts (TCC) in the management of plantar neuropathic ulcers, a practice first described for the management of foot ulcers in leprosy in India and Ceylon (now Sri Lanka) prior to the introduction of antibiotics [3]. 
The principle of TCC management is that pressure is mitigated, but in addition, as the device is irremovable, compliance with the treatment is enforced and mobility is reduced. Following a number of published case series (e.g. [82]), the first randomised trial of casting was published by Mueller et al. in 1989 [83]. This study, in which the TCC was compared with accommodative footwear, reported significantly faster healing in the TCC, with an absolute risk reduction of $59 \%$.

As a result of this randomised study and previous case series, TCC was accepted as the gold standard by the American Diabetes Association [28], although a systematic review concluded that further confirmatory studies were required [84].

A second randomised trial was performed, in which the TCC was compared with a removable cast walker (RCW) and a half shoe [85]. Again, the TCC proved to be superior to the other two modalities in terms of time needed to complete healing. Patients in the TCC were also significantly less active as measured by steps per day. However, as previous gait laboratory studies had confirmed that the RCW reduces pressure to approximately the same degree as the TCC $[86,87]$, the question remained as to why the TCC was superior in terms of wound healing compared with the RCW. One strong possibility relates to patient compliance. While the TCC was irremovable, the RCW was removable by definition. This hypothesis was therefore tested in a study of 20 subjects with plantar ulcers provided with removable cast walkers [88]. Total activity (measured in activity steps per day) was recorded from a waistworn computerised accelerometer (pedometer). This activity was subsequently correlated to activity recorded on an RCW-mounted accelerometer, which was neither visible nor accessible to the patient. Although patients were advised to wear the RCW whenever walking, this study showed that only $28 \%$ of daily activity was taken whilst wearing the RCW. Thus, most of the activity of neuropathic foot ulcer patients is undertaken without offloading, which might partially explain the poor outcome of many trials of proposed new agents (e.g. [89]) that have not used effective offloading.

Problems with the TCC include the level of skill required to apply the device, the expense of time and materials (the device should be removed and replaced weekly) and the potential of a rigid cast to injure the neuropathic foot $[78,82,85]$. Accordingly, an alternative to the TCC was proposed, by Armstrong et al., and named the "instant total-contact cast" [90]. This technique involves taking an RCW and rendering it irremovable by wrapping it with one or two bands of plaster of paris (Fig. 3), thereby addressing most of the disadvantages of the TCC but preserving irremovability. A preliminary randomised trial of the TCC versus the instant TCC in the management of plantar neuropathic foot ulcers has confirmed not only equivalent efficacy of the two devices, but also that the instant TCC is cheaper, quicker to apply and has fewer
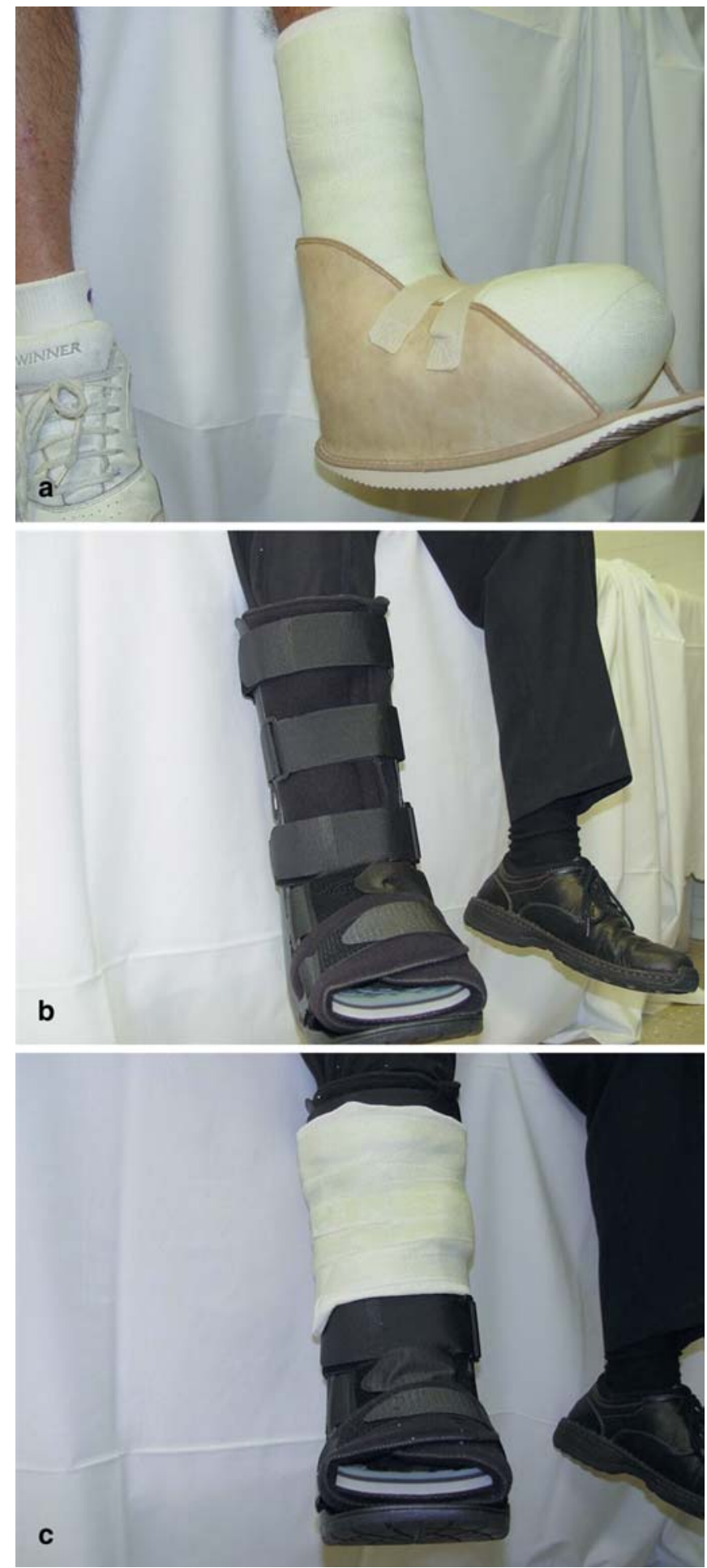

Fig. 3 a. A typical total-contact cast using the treatment of neuropathic foot ulcers. b. A patient wearing a removable cast walker (DH Walker, Royce Medical, Camarillo, Calif., USA). c. "Instant total-contact cast". The removable cast walker shown in $\mathbf{b}$ has now been rendered irremovable by the application of bands of casting

adverse effects than the traditional TCC [91]. As this device does not require a skilled technician to apply it, it could revolutionise the future management of plantar neuropathic ulcers. 
Offloading and wound healing. The effects of pressure relief on the histopathological features of neuropathic ulcers was recently assessed in a randomised study [92] from Pisa, where ulcerectomy is routinely performed for plantar ulcers. Patients with chronic neuropathic ulcers were randomised to ulcerectomy at presentation or after 20 days of offloading in a TCC. While histological features of chronic inflammation, with mononuclear cell infiltration, cellular debris and scarce evidence of angiogenesis or granulation, were seen in patients who underwent ulcerectomy at presentation, granulation neo-angiogenesis and a predominance of fibroblasts were seen in the casted patients [92]. These important observations strongly suggest that repetitive pressure on a neuropathic wound contributes to the chronicity of the wound, whereas pressure relief results in the wound appearing, in several respects, more like an acute wound in the reparative phase.

Other factors in the chronicity of wounds. Recent studies have also demonstrated other abnormalities frequently seen in chronic neuropathic diabetic foot ulcers. Jude et al. described the lack of up-regulation of TGF- $\beta 1$ in foot ulcers, and Lobmann and colleagues described increases in matrix metalloproteinases and decreased concentration of their inhibitors, both of which could explain impaired wound healing $[79,80]$. A lack of insulin-like growth factor-1 in the basal keratinocyte layer of biopsies from foot ulcers [93], and increased nitric oxide synthase activity in foot ulcers [94] may also be contributory to retarded wound healing in diabetes.

Recent studies suggest that psychological distress (depression and anxiety) is common in diabetic patients with neuropathy and foot ulcers [38]. This could impact on wound healing in two ways: (i) poor foot care and reduced compliance with offloading is more likely in depressed patients $[38,95]$; (ii) there is substantial evidence that factors such as stress, negative affect and/or lack of social support have adverse consequences for the wound healing response. Stress has been shown to delay wound healing, possibly by altering proinflammatory cytokine production [96, 97]. In addition, depressive symptoms might, via the hypothalamic pituitary adrenal and sympathetic adrenal medullary axes, mediate matrix metalloproteinase levels, thereby impacting on wound healing [98].

In summary, the area of wound healing and diabetes is extremely complex, but recent research would suggest that repetitive stresses on diabetic foot ulcers play a major part in maintaining the chronicity of the wound. In the near future, gene therapy for certain chronic wounds is likely to become reality [99]. Similarly, as pluripotential stem cells are capable of differentiating into a variety of cell types including fibroblasts and keratinocytes, stem cell therapy may be efficacious in chronic wounds. Preliminary data have suggested that autologous bone marrow cells ap- plied to chronic wounds might accelerate healing [100].

\section{International developments}

Diabetic foot problems remain common all over the world, but are particularly prone to result in amputation in developing countries [101, 102]. While risk factors for ulceration appear to be similar among European countries [103], differences do exist between European and African and Asian countries, with vascular disease being less common in developing countries [104]. In view of the global problem of diabetic foot disease, the International Working Group on the Diabetic Foot was created about 10 years ago, which later became an official consultative section of the International Diabetes Federation in 2001. This group published an international consensus document and practical guidelines on the management and prevention of the diabetic foot in 1999 (http://www.diabetic-foot-consensus.com). A further consensus document on diagnosing and treating diabetic foot infections was recently published [105]. It is hoped that the continuing activities of groups such as these, in combination with a better understanding of the science of foot wounds and their healing, will result in fewer ulcers and amputations as well as in improved quality of life for our diabetic patients in the 21 st century.

\section{References}

1. Pryce TD (1887) A case of perforating ulcers of both feet associated with diabetes and ataxic symptoms. Lancet 2:11-12

2. Boulton AJM (1990) Lawrence Lecture: the diabetic foot: neuropathic in aetiology? Diabetic Med 7:852-858

3. Brand PW (1983) The Diabetic Foot. In: Ellenberg M, Rifkin H (eds) Diabetes mellitus: theory and practice, 3rd edn. Med Exam Publishing, New York, pp 829-849

4. Bauman JH, Brand PW (1963) Measurement of pressure between foot and shoe. Lancet 1:629-632

5. Bergtholdt HT, Brand PW (1976) Temperature assessment and plantar inflammation. Lepr Rev 47:211-219

6. International Working Group on the Diabetic Foot (1999) International consensus on the diabetic foot. Amsterdam, The Netherlands

7. Shaw JE, Zimmett PZ (1999) The epidemiology of diabetic neuropathy. Diabetes Rev 6:245-252

8. Williams DRR, Airey M (2000) The size of the problem: epidemiological and economic aspects of the diabetic foot. In: Boulton AJM, Connor H, Cavanagh PR (eds) The foot in diabetes, 3rd edn. Wiley, Chichester, pp 3-17

9. Reiber GE, Ledoux WR (2002) Epidemiology of diabetic foot ulcers and amputations: evidence for prevention. In: Williams R, Herman W, Kinmonth AL, Wareham NJ (eds) The evidence base for diabetes care. Wiley, Chichester, pp 641-665

10. Carrington AL, Abbott CA, Griffiths J, Jackson N, Ross ERE van, Boulton AJM (2001) A foot care program for diabetic unilateral amputees. Diabetes Care 24:216-221 
11. Kumar S, Ashe H, Fernando DJS, Tsigos C, Young RJ, Boulton AJM (1994) The prevalence of foot ulceration and its correlates in type 2 diabetic patients: a population-based study. Diabetic Med 11:480-484

12. Abbott CA, Carrington AL, Ashe H et al. (2002) The North-West Diabetes Foot Care Study: incidence of, and risk factors for, new diabetic foot ulceration in a community-based patient cohort. Diabetic Med 20:377-384

13. Muller IS, Grauw WJ de, Gerwen WH van et al. (2002) Foot ulceration and lower limb amputation in type 2 diabetic patients in Dutch primary health care. Diabetes Care 25:570-574

14. Lavery LA, Armstrong DG, Wunderlich RP, Tredwell J, Boulton AJM (2003) Diabetic foot syndrome: evaluating the prevalence and incidence of foot pathology in Mexican Americans and non-Hispanic whites from a diabetes management cohort. Diabetes Care 26:1435-1438

15. Humphrey ARG, Thomas K, Dowse GK, Zimmet PZ (1996) Diabetes and non-traumatic lower extremity amputations. Incidence, risk factors and prevention: a 12 year follow-up study in Nauru. Diabetes Care 19:710-716

16. Behhadj MA (1998) La place du pied diabetique [in French]. Diabete Metab 24 [Suppl 1]:LXVII

17. Pendsey S (1994) Epidemiological aspects of the diabetic foot. J Diabetes Develop Countries 2:37-38

18. Young MJ, Veves A, Breddy JL, Boulton AJM (1994) The prediction of diabetic neuropathic foot ulceration using vibration perception thresholds: a prospective study. Diabetes Care 17:557-560

19. Abbott CA, Vileikyte L, Williamson S, Carrington AL, Boulton AJM (1998) Multicentre study of the incidence of and predictive factors for diabetic neuropathic foot ulcers. Diabetes Care 21:1071-1075

20. Larsson J, Apelqvist J, Agardh GD, Stenstrom A (1995) Decreasing incidence of major amputation in diabetic patients: a consequence of a multidisciplinary foot care team approach? Diabetic Med 12:770-776

21. Trautner C, Haastert B, Spraul M, Giani C, Berger M (2001) Unchanged incidence of lower limb amputations in a German city 1990-1998. Diabetes Care 24:855-859

22. Trautner C, Haastert B, Giani C, Berger M (2002) Amputations and diabetes: a case-control study. Diabetic Med 19:35-40

23. No authors listed (1997) An audit of amputations in a rural health district. Practical Diabetes Int 14:175-178

24. Toledano H, Young MJ, Veves A, Boulton AJM (1993) Why do Asian diabetic patients have fewer foot ulcers than Caucasians? Diabetic Med 10 [Suppl 1]:539

25. Chaturvedi N, Abbott CA, Whalley A, Leggetter SY, Boulton AJM (2002) Risk of diabetes-related amputation in south Asians vs Europeans in the UK. Diabetic Med 19:99-106

26. Leggetter SY, Chaturvedi N, Fuller JH, Edmonds ME (2001) Ethnicity and risk of diabetes-related lower extremity amputation: a population-based, case-control study of Afro-Caribbeans and Europeans in the United Kingdom. Arch Int Med 162:73-78

27. Resnick HE, Valsania P, Phillips CL (1999) Diabetes mellitus and non-traumatic lower extremity amputation in black and white Americans: the national health and nutrition examination survey epidemiology follow-up study 19711992. Arch Int Med 159:2470-2475

28. American Diabetes Association (1999) Consensus development conference on diabetic wound care. Diabetes Care 22:1354-1360

29. Shearer A, Scuffham P, Gordois A, Ogleshy A (2003) Predicted costs and outcomes from reduced vibration detection in people with diabetes in the US. Diabetes Care 26:2305-2310
30. Ragnarson-Tennvall G, Apelqvist J (2001) Prevention of diabetes-related foot ulcers and amputations: a cost-utility analysis based on Markov model simulation. Diabetologia 44:2077-2087

31. Assal JP, Mehnert H, Tritschler HS, Sidorenko A, Keen H (2002) 'On your feet' workshop on the diabetic foot. J Diabet Comp 16:183-194

32. Ramsey SD, Newton K, Blough D et al. (1999) Incidence outcomes and costs of foot ulcers in patients with diabetes. Diabetes Care 22:382-387

33. Boulton AJM (2000) The pathway to ulceration: aetiopathogenesis. In: Boulton AJM, Connor H, Cavanagh PR (eds) The foot in diabetes, 3rd edn. Wiley, Chichester, pp 19-31

34. Reiber GE, Vileikyte L, Boyko EJ et al. (1999) Causal pathway for incident lower extremity ulcers in patients with diabetes from two settings. Diabetes Care 22:157-162

35. Boulton AJM, Hardisty CA, Betts RP et al. (1983) Dynamic foot pressure and other studies as diagnostic and management aids for diabetic neuropathy. Diabetes Care 6:26-33

36. Katoulis EC, Ebdon-Parry M, Hollis S et al. (1997) Postural instability in diabetic patients at risk of foot ulceration. Diabetic Med 14:296-300

37. Katoulis EC, Ebdon-Parry M, Lanshammar H et al. (1997) Gait abnormalities in diabetic neuropathy. Diabetes Care 20:1904-1907

38. Vileikyte L, Rubin RR, Leventhal H (2004) Psychological aspects of diabetic neuropathy and its late sequelae. Diab Metab Res Rev 20 [Suppl 1]:S13-S18

39. Young MJ, Boulton AJM, MaCleod AF, Williams DRR, Sonksen PH (1993) A multicentre study of the prevalence of diabetic peripheral neuropathy in the UK hospital clinic population. Diabetologia 36:150-154

40. Mayfield JA, Sugarman JR (2000) The use of the SemmesWeinstein monofilament and other threshold tests for preventing foot ulceration and amputation in persons with diabetes. J Fam Pract 49 [Suppl 11]:S17-S29

41. Booth J, Young MJ (2000) Differences in the performance of commercially available monofilaments. Diabetes Care 23:984-988

42. Miranda-Palma B, Basu S, Mizel MS et al. (2003) The monofilament as the gold standard for foot ulcer risk screening: a reappraisal. Diabetes 53 [Suppl 1]:A63

43. Carrington AL, Shaw JE, Van Schie CHM, Abbott CA, Vileikyte L, Boulton AJM (2002) Can motor nerve conduction velocity predict foot problems in diabetes over a six year outcome period? Diabetes Care 25:2010-2015

44. Jude EB, Oyibo SO, Chalmers N, Boulton AJM (2001) Peripheral arterial disease in diabetic and non-diabetic patients: a comparison of severity and outcome. Diabetes Care 24:1433-1437

45. Lavery LA, Armstrong DG, Vela SA et al. (1998) Practical criteria for screening patients at high risk of diabetic foot ulceration. Arch Int Med 26:157-162

46. Murray HJ, Young MJ, Boulton AJM (1996) The relationship between callus formation, high pressures and neuropathy in diabetic foot ulceration. Diabetic Med 13:979-982

47. Valk GD, Kriegsman DM, Assendelf WJ (2002) Patient education for reducing diabetic foot ulceration: a systematic review. Endocrinol Metab Clin N Amer 31:633-658

48. McCabe CJ, Stevenson RC, Dolan AM (1998) Evaluation of a diabetic foot screening and prevention programme. Diabetic Med 15:80-84

49. Vileikyte L (2000) Psychological and behavioural issues in diabetic neuropathic foot ulceration. In: Boulton AJM, Connor H, Cavanagh PR (eds) The foot in diabetes, 3rd edn. Wiley, Chichester, pp 121-130 
50. Veves A, Boulton AJM (1993) The optical pedobarograph. Clin Podiatr Med Surg 10:463-470

51. Boulton AJM, Betts RP, Franks CI et al. (1987) Abnormalities of foot pressure in early diabetic neuropathy. Diabetic Med 4:225-228

52. Boulton AJM, Betts RP, Franks CI, Ward JD, Duckworth T (1987) The natural history of foot pressure abnormalities in neuropathic diabetic subjects. Diabetes Res 5:73-77

53. Newrick PG, Cochrane T, Betts RP, Ward JD, Boulton AJM (1988) Reduced hyperaemic response under the neuropathic diabetic foot. Diabetic Med:570-573

54. Masson EA, Hay EM, Stockley I, Betts RP, Boulton AJM (1989) Abnormal foot pressures alone may not cause ulceration. Diabetic Med 6:426-429

55. Young MJ, Cavanagh PR, Thomas G et al. (1992) The effect of callus removal on dynamic plantar foot pressures in diabetic patients. Diabetic Med 9:55-57

56. Veves A, Young MJ, Murray HJ, Boulton AJM (1993) The risk of foot ulceration in diabetic patients with high foot pressures: a prospective study. Diabetologia 35:660-663

57. Lavery LA, Armstrong DG, Wunderlich RP, Tredwell J, Boulton AJM (2003) Predictive value of foot pressure assessment when part of a population-based diabetes disease management program. Diabetes Care 26:1069-1073

58. Cavanagh PR, Ulbrecht JS, Caputo GM (2000) What the practicing physician should know about diabetic foot biomechanics. In: Boulton AJM, Connor H, Cavanagh PR (eds) The foot in diabetes, 3rd edn. Wiley, Chichester, pp 33-60

59. Van Schie CHM, Abbott CA, Vileikyte L, Shaw JE, Hollis S, Boulton AJM (1999) A comparative study of Podotrack, a simple semiquantitative plantar pressure measuring device and the optical pedobarograph in the assessment of pressures under the diabetic foot. Diabetic Med 16:154-159

60. Bygrave CJ, Betts RP (1993) The Plantar tissue thickness in the foot: a new ultrasound technique for load-bearing measurements and a metatarsal head depth study. Foot 3:71-79

61. Abouaesha F, van Schie CHM, Griffiths GD, Young RJ, Boulton AJM (2001) Plantar tissue thickness is related to peak plantar pressure in the high risk diabetic foot. Diabetes Care 24:1270-1274

62. Abouaesha F, Schie CHM van, Armstrong DG, Boulton AJM (2004) Plantar soft tissue thickness predicts high peak plantar pressure in the diabetic foot. J Am Podiatr Med Assoc 94:39-42

63. Herring KM, Richie DH (1990) Friction blisters and sock fiber composition: a double-blind study. J Am Podiatr Med Assoc 80:63-71

64. Veves A, Masson EA, Fernando DJS, Boulton AJM (1989) Use of experimental padded hosiery to reduce abnormal foot pressures in diabetic neuropathy. Diabetes Care 12:653-655

65. Murray HJ, Veves A, Young MJ, Richie DH, Boulton AJM (1993) Role of experimental socks in the care of the highrisk diabetic foot. A multicentre evaluation study. Diabetes Care 16:1190-1192

66. Balkin S, Kaplan L (1991) Injectable silicone and the diabetic foot. A 25 year report. Foot 2:83-88

67. Van Schie CHM, Whalley A, Vileikyte L, Wignall T, Hollis S, Boulton AJM (2000) Efficacy of injected liquid silicone in the diabetic foot to reduce risk factors for ulceration: a randomized double-blind placebo-controlled trial. Diabetes Care 23:634-638

68. Van Schie CHM, Whalley A, Vileikyte L, Boulton AJM (2002) Efficacy of injected liquid silicone is related to peak plantar foot pressures in the neuropathic diabetic foot. Wounds 14:26-30
69. Van Schie CHM, Whalley A, Armstrong DG, Vileikyte L, Boulton AJM (2002) The effect of silicone injections in the diabetic foot on peak plantar pressure and plantar tissue thickness: a 2 year follow-up. Arch Phys Med Rehabil 83:919-923

70. Shaw JE, Boulton AJM (1995) The Charcot foot. Foot 5:65-70

71. Young MJ, Marshall A, Adams JE, Selby PL, Boulton AJM (1995) Osteopenia, neurological dysfunction and the development of Charcot neuroarthropathy. Diabetes Care 18:34-38

72. Selby PL, Young MJ, Boulton AJM (1994) Bisphosphonates: a new treatment for diabetic Charcot neuroarthropathy? Diabetic Med 11:28-31

73. Gough A, Abraha H, Purewal TS et al. (1997) Measurement of markers of osteoclastic and osteoblastic activity in patients with acute and chronic diabetic Charcot neuroarthropathy. Diabetic Med 14:517-531

74. Selby PL, Burgess J, Jude EB et al. (1998) Bone turnover markers in acute Charcot neuroarthropathy. Diabetologia 41 [Suppl 1]:A275

75. Jude EB, Selby PL, Burgess J et al. (2001) Bisphosphonates in the treatment of Charcot neuroarthropathy: a double-blind randomized controlled trial. Diabetologia 44:2032-2037

76. McGill M, Molyneux L, Balton T et al. (2000) Response of Charcot's arthropathy to contact casting: skin temperature and radiographic correlates. Diabetologia 43:481-484

77. Thomas DW, Harding KG (2002) Wound healing. Br J Surg 89:1203-1205

78. Jeffcoate WJ, Harding KG (2003) Diabetic foot ulcers. Lancet 361:1545-1551

79. Jude EB, Blakytny R, Bulmer J, Boulton AJM, Ferguson MWJ (2002) Transforming growth factor-beta 1, 2, 3 and receptor type 1 and 2 in diabetic foot ulcers. Diabetic Med 19:440-447

80. Lobmann R, Ambrosch A, Schultz G et al. (2002) Expression of matrix-metalloproteinases and their inhibitors in the wounds of diabetic and non-diabetic patients. Diabetologia 45:1011-1016

81. Boulton AJM, Armstrong DG (2003) Studies in plantar diabetic neuropathic ulcers; time for a paradigm shift? Diabetes Care 26:2689-2690

82. Boulton AJM, Bowker JH, Gadia M et al. (1986) Use of plaster casts the management of diabetic neuropathic foot ulcers. Diabetes Care 9:149-152

83. Mueller MJ, Diamond JE, Sinacore DR et al. (1989) Total contact casting in the treatment of diabetic plantar ulcers: controlled clinical trial. Diabetes Care 12:384-388

84. Mason J, O'Keeffe C, Hutchinson A, McIntosh A, Young R, Booth A (1999) A systematic review of foot ulcers in patients with type 2 diabetes mellitus II treatment. Diabetic Med 16:889-909

85. Armstrong DG, Nguyen HC, Lavery LA, Van Schie CHM, Boulton AJM, Harkless LB (2001) Offloading the diabetic foot wound: a randomized clinical trial. Diabetes Care 24:1019-1022

86. Lavery LA, Vela SA, Lavery DC, Quebedeaux TL (1996) Reducing dynamic foot pressures in high-risk diabetic subjects with foot ulcerations: a comparison of treatments. Diabetes Care 19:818-821

87. Baumhauer JF, Wervery R, McWilliams J, Harris GF, Shereff MJ (1997) A comparison study of plantar foot pressure in a standardized shoe, total contact cast prefabricated pneumatic walking brace. Foot Ankle Int 18:2633 
88. Armstrong DG, Lavery LA, Kimbriel HR, Nixon BP, Boulton AJM (2003) Activity patterns of patients with diabetic foot ulceration: patients with active ulceration may not adhere to a standard pressure offloading regimen. Diabetes Care 26:2595-2597

89. Veves A, Sheehan P, Pham HT (2002) A randomized controlled trial of Promogran vs standard treatment in the management of diabetic foot ulcers. Arch Surg 137:822-827

90. Armstrong DG, Short B, Espensen EH, Abu-Ramman PL, Nixon BP, Boulton AJM (2002) Technique for fabrication of an 'instant total contact cast' for treatment of neuropathic diabetic foot ulcers. J Am Pod Med Assoc 92:405-408

91. Katz I, Harlan A, Miranda-Palma B et al. (2004) A randomised trial of two irremovable offloading devices in the management of plantar neuropathic diabetic foot ulcers. Diabetes 54 [Suppl]:A85

92. Piaggesi A, Viacava P, Rizzo L et al. (2003) Semi-quantitative analysis of the histopathological features of the neuropathic foot ulcer-effects of pressure relief. Diabetes Care 26:3123-3128

93. Blakytny R, Jude EB, Gibson JM, Boulton AJM, Feguson MWJ (2000) Lack of insulin-like growth factor 1 (IGF-1) in the basal keratinocyte layer of diabetic skin and diabetic foot ulcers. J Pathol 190:589-594

94. Jude EB, Boulton AJM, Ferguson MWJ, Appleton I (1999) The role of nitric oxide synthase isoforms and arginase in the pathogenesis of diabetic foot ulcers: possible modulatory effectors of transforming growth factor beta 1. Diabetologia 42:748-757

95. Boulton AJM, Kirsner RS, Vileikyte L (2004) Neuropathic diabetic foot ulcers. N Engl J Med 351:48-55
96. Glaser R, Kiecolt-Glaser JK, Maruchas PT et al. (1999) Stress-related changes in proinflammatory cytokine production in wounds. Arch Gen Psychiatry 56:450-456

97. Kiecolt-Glaser J, Preacher JK, MacCallum RC et al. (2003) Chronic stress and age-related increases in the proinflammatory cytokine IL-6. Proc Natl Acad Sci USA 100:9090-9095

98. Yang EV, Bone CM, MacCallum RC et al. (2002) Stress related modulation of matrix metalloproteinase expression. J Neuroimmunol 133:144-150

99. Badiavas EV, Falanga V (2001) Gene therapy. J Dermatol 138:1079-1081

100. Badiavas EV, Falanga V (2003) Treatment of chronic wounds with bone marrow-derived cells. Arch Dermatol 139:510-516

101. Naraynsingh V, Singh M, Ramdass MJ et al. (2002) Major lower limb amputation in Trinidad: a retrospective analysis. Diabetic Foot 5:81-83

102. Abbas ZG, Gill GV, Archibald LK (2002) The epidemiology of diabetic limb sepsis: an African perspective. Diabetic Med 19:895-899

103. Veves A, Uccioli L, Manes C et al. (1994) Comparison of risk factors for foot problems in diabetic patients attending teaching hospitals in four different European states. Diabetic Med 11:709-713

104. Morbach S, Lutale JK, Viswanathan V et al. (2004) Regional differences in risk factors and clinical presentation of diabetic foot lesions. Diabetic Med 21:91-95

105. Lipsky BA (2004) A report from the International Consensus on diagnosing and treating the infected diabetic foot. Diabet Met Res Rev 20 [Suppl 1]:S68-S77 